\title{
Urdimento
}

Revista de Estudos em Artes Cênicas

E-ISSN: 2358.6958

\section{O Axis Mundi e o Jogo Ritual: Deslocamento da realidade imanente para se alcançar a Hierofania}

Saulo Vinícius Almeida

Robson Carlos Haderchpek

\section{Para citar este artigo:}

ALMEIDA, Saulo Vinicius; HARDECHPEK, Robson. O Axis Mundie o Jogo Ritual: Deslocamento da realidade imanente para se alcançar a Hierofania. Urdimento, Florianópolis, v. 2, n. 38, ago./set. 2020.

DOI: http:/dx.doi.org/10.5965/14145731023820200017

Este artigo passou pelo Plagiarism Detection Software | iThenticate 
O Axis Mundi e o Jogo Ritual:

Deslocamento da realidade imanente para se alcançar a Hierofania

Saulo Vinícius Almeida

Robson Carlos Haderchpek²

\begin{abstract}
Resumo
O presente artigo se propõe a analisar as práticas de criação cênica do Grupo Arkhétypos à luz do Jogo Ritual relacionando-o com o conceito de axis mundi proposto por Mircea Eliade e as teorias do imaginário de Gilbert Durand. Trabalhase com a hipótese de que a experiência do mito manifestada no corpo do ator reorganiza a relação espaço-temporal permitindo ao público um deslocamento da realidade imanente para que se possa alcançar a hierofania. A fim de elucidar a questão desenvolvemos uma breve reflexão a partir dos espetáculos Santa Cruz do Não Sei (2011) e Revoada (2014) e lançamos um olhar crítico frente ao processo de colonização sofrido nas Américas.
\end{abstract}

Palavras-Chave: Axis Mundi. Jogo Ritual. Mito. Teatro Sagrado. Imaginário.

The Axis Mundiand the Ritual Play:

Displacement of immanent reality to achieve Hyerophani

\begin{abstract}
This article proposes to analyze the scenic creation practices of the Arkhétypos Group in the light of the Ritual Game, relating it to the concept of axis mundi proposed by Mircea Eliade and the theories of the imaginary of Gilbert Durand.. We work with the hypothesis that the experience of myth manifested in the actor's body reorganizes the spatio-temporal relationship, allowing the public to displace the immanent reality so that hierophany can be achieved. In order to clarify the issue, we developed a brief reflection from the plays Santa Cruz do Não Sei (2011) and Revoada (2014) and we take a critical look at the colonization process suffered in the Americas.
\end{abstract}

Keywords: Axis Mundi. Ritual Play. Myth. Sacred Theatre. Imaginary.

1 Mestrando em Artes Cênicas na Universidade de São Paulo (ECA/USP). sauloalmeida@uso.br

2 Professor Associado do Curso de Teatro da Universidade Federal do Rio Grande do Norte (UFRN). Atua no Programa de Pós-Graduação em Artes Cênicas. Pós-doutorado na Universtät für Musik und Darstellende Kunst Wien, Áustria (2014-2015). Rob hader@yahoo.com.br 
O espaço não é anterior à experiência, ele se dá a partir da confluência de espacialidades geográficas e da subjetividade dos sujeitos. O espaço cenográfico, como nos lembra Doris Rollemberg (2012), é uma instância relacional que se estabelece para além da tridimensionalidade, pois abarca a quarta dimensão: o tempo, resultante da experiência de deslocamento dos corpos pelo espaço. E, para além dessa relação espaço-temporal, se "pressente a sugestão de outra dimensão que existirá a partir da relação com o observado" (2012, p. 6). O Grupo Arkhétypos joga com essas dimensões da construção sensível do espaço criando uma arte ritual que busca a partir da transformação dos estados dos atores, da atualização constante de mitos e arquétipos, da manipulação da iluminação e de sonoridades criar espaços que carregam em si a condição de axis mundi e transportam o público para um tempo-espaço mítico.

Há dez anos o Grupo Arkhétypos pesquisa essa relação entre o tempoespaço mítico e a cena, e as produções artísticas do grupo, de um modo geral, sempre buscam deslocar o público da realidade imanente e alçá-lo à hierofania. Todavia, faz-se mister esclarecer que a manifestação do sagrado não é entendida no grupo a partir de uma vertente religiosa, e não está condicionada à uma visão de mundo materialista, eurocêntrica e maniqueísta.

O sagrado ao qual nos referimos traduz-se a partir de uma relação íntima do ser consigo mesmo, e para que essa experiência ocorra no universo teatral o público precisa se sentir seguro para se entregar à cena. Deste modo, o grupo trabalha para que durante o momento em que vive a experiência da cena, o público possa se descolar da realidade imanente e adentre numa espécie de espaço sagrado, como se um portal dimensional fosse aberto na relação mágico-ficcional

\footnotetext{
3 O Arkhétypos é um Grupo de Teatro da Universidade Federal do Rio Grande do Norte (UFRN), vinculado ao Departamento de Artes, do Centro de Ciências Humanas, Letras e Artes. É coordenado por Robson Haderchpek, professor da Licenciatura em Teatro e do Programa de Pós-Graduação em Artes Cênicas da UFRN, e composto por estudantes e docentes desses cursos, além de contar com colaboradores de áreas afins. Desde sua criação, em 2010, o Grupo atua nas áreas da pesquisa e da extensão, desenvolvendo processos criativos e produzindo espetáculos teatrais que almejam estabelecer proximidade na relação entre a comunidade e o meio artístico-acadêmico. Produziu onze espetáculos, tendo sido tema de cinco projetos de pesquisa, dezessete trabalhos de conclusão de curso, sete dissertações de mestrado, uma tese de doutorado e três pesquisas de pós-doutorado, além de também ser tema de dois livros, três capítulos de livro e doze artigos científicos (para maiores informações, pode-se consultar a página do Grupo na internet: https://arkhetyposgrupodet.wixsite.com/arkhetypos. Acesso em: 01 maio 2020.
} 
da cena.

O axis mundié um termo que permeia a obra de Mircea Eliade e compreende a noção de centro do mundo, podendo ser representado por uma montanha, um totem, o centro da roda ao redor da qual dançam os religiosos ou as deidades, um templo, ou mesmo a coluna vertebral. Ele é o eixo cósmico que liga o céu, a terra e o subterrâneo em suas dimensões metafóricas.

\begin{abstract}
Detenhamo-nos um instante nesta imagem mítica: o zénite - que é simultaneamente o Topo do Mundo e o «Centro» por excelência, o ponto infinitesimal por onde passa o Eixo Cósmico (Axis Mundi). [...] Um «Centro» representa um ponto ideal, pertencente não ao espaço profano, geométrico, mas ao espaço sagrado e no qual se pode realizar a comunhão com o céu ou o Inferno; noutros termos, um «Centro» é o lugar paradoxal da ruptura dos níveis, o ponto onde o mundo sensível pode ser transcendido. Mas pelo próprio fato de transcender-se o Universo, o mundo criado, transcende-se o tempo, a duração, e obtém-se o êxtase, o eterno presente intemporal. (Eliade, 1979a, p. 74).
\end{abstract}

A sacralização do espaço e a anulação do tempo histórico (profano) frente à instauração de uma temporalidade mítica, de uma experiência espaço-temporal que atualiza uma narrativa de illo tempore é resultado da eficácia mágicosimbólica do ritual. Tal eficácia não se fundamenta apenas em um conjunto de crenças, condutas e símbolos compartilhados por um determinado grupo, mas se concretiza nas transformações e afecções que provoca, assim como em seus efeitos, na adesão implicada em sua realização. (Chiesa, 2014).

O ritual agencia o corpo de tal maneira que o retira do tempo e do espaço, desloca-o para um fora que é ao mesmo tempo ficcional e real, compreendendo aqui o real na chave do transcendente, daquilo que se encontra no mundo das realidades absolutas. Cria um "corpo utópico" que se projeta para fora de "todos os lugares" adentrando e sendo adentrado pelo espaço do sagrado, do religioso, do contra-mundo, afinal "o corpo do dançarino não é justamente um corpo dilatado segundo um espaço que the é ao mesmo tempo interior e exterior?" (Foucault, 2013, p. 14). 


\section{O Axis Mundi e o Jogo Ritual}

Ao ouvir o termo ritual em um vínculo com o teatro, a maioria de nós realiza uma referência direta com as propostas grotowskianas ou artaudianas, contudo, estamos defronte um resultado estético que já está longe daqueles. A prática do grupo se pauta no Jogo Ritual, termo que reflete uma busca pela origem primitiva do jogo e que remete ao universo cultural dos povos que habitavam a América pré-colonial:

O que o "jogo ritual" retoma é a origem primitiva do jogo e propõe uma situação entre, ou seja, um jogo em que o espectador é convidado a observar e a interagir com a cena, emancipando-o da situação de mero espectador e atribuindo-lhe o papel de viver o sentido da cena junto com o ator. Na proposta do "jogo ritual" as fronteiras entre palco e plateia são borradas e o público participante integra o ato de comunhão ritualístico completando o sentido da ação [...]. Este tipo de jogo remete a uma ação própria dos rituais dos povos antigos, povos estes que habitavam a América antes da colonização e que traziam saberes que podem e devem ser resgatados. (Haderchpek, 2018, p. 60-61).

Nos rituais, assim como nas sociedades que se organizam a partir de um conjunto de mitos, a organização do espaço atualiza o mito cosmogônico que the deu origem, assim como, possibilita a instauração desse outro tempo. Tomemos como exemplo a organização do espaço nas comunidades dos Achilpas australianos e dos boborós, do Mato Grosso, narrados por Mircea Eliade (1979b).

Segundo o mito cosmogônico do povo Achilpas, após Numbakula, o ancestral e criador divino, ter organizado o caos e criado o território e as instituições em que vivem, ele retornou ao céu fazendo uso de um tronco de eucalipto. Desde então, os membros dessa comunidade nômade carregavam sempre consigo um tronco de eucalipto como forma de criar o seu mundo nos espaços em que se encontravam. A falta desse eixo vertical que os ligava ao sagrado tornava insustentável a vida e levava os Achilpas a deixarem-se morrer. Já no caso dos bororós brasileiros, Eliade aponta que a cosmogonia desse grupo se refletia em um desenho de aldeia que se organizava a partir de dois eixos, dividindo-a em quatro. Uma espécie de círculo irregular ao redor do que denominavam como 
terreno de danças e casa dos homens. A vida social e a estrutura de parentesco organizavam-se em sintonia com a organização espacial e quando esta foi desfeita por missionários Salesianos que os convenceu a estabelecer um novo formato para a aldeia, eles ficaram extremamente desorientados. O autor aponta, que a partir de então, estando apartado de sua cosmologia original, esse povo passou a aceitar as explicações Salesianas para organização e significação do universo novo e confuso que se apresentava a eles. O mito organiza a vida, norteia o ser protegendo-o do abandono no caos.

Os rituais se configuram como uma atualização dos gestos cosmogônicos, alçando os envolvidos para um tempo cósmico, o tempo das origens. Ao se instaurar um gesto cosmogônico, sacraliza-se o espaço religando o céu e a terra a partir do centro desse ritual, que corresponde ao centro do mundo, ao axis mundi. Por tal motivo, encontramos nas mais diversas manifestações populares o formato cêntrico, circular. Se tomarmos o exemplo do candomblé, como salienta Ligiéro (2019, p. 87), veremos que é no centro que "estão enterrados os assentamentos e onde se encontra a grande força, o axé”.

O primeiro espetáculo do Grupo Arkhétypos chamado "Santa Cruz do Não Sei” já trazia em si uma proposta de rompimento com o espaço cênico convencional e adotava a circularidade como princípio ritualístico, fazendo alusão ao axis mundi. O primeiro processo de criação do grupo foi desenvolvido a partir de histórias de pescadores e ao longo do espetáculo realizavam-se vários ritos. Ao adentrar ao espaço o público era convidado a se sentar em roda, ao lado dos atores, e então ele era transportado para outro lugar, um lugar mágico-simbólico, repleto de sons enigmáticos que remetiam a um chamado, tal como o sopro dos ventos sob o mar à noite.

No espetáculo os atores cantavam, celebravam a vida, e partilhavam as histórias de pescador que foram inspiradas pela comunidade da Vila de Ponta Negra, Natal/RN. Ao longo do espetáculo os atores encenavam o rito de partida dos pescadores que iam para o mar, a festa feita pela comunidade na chegada dos barcos repletos de peixe, bem como os momentos de devoção à Yemanjá e o rito de espera das viúvas que perderam seus homens no mar. 
O trabalho todo era conduzido dentro da perspectiva do Jogo Ritual e dentro dele os atores, dançavam, cantavam, tocavam alfaia, percussão e criavam um espaço cênico que remetia a uma vila de pescadores que foi tragada pelo mar. Caiam do teto pequenos corais de concha que visavam criar no público a impressão de submersão e isso tudo contribuía para a construção de uma atmosfera onírica que envolvia o espectador, tornando-o parte da ação. A seguir temos uma imagem do espetáculo, nela podemos notar o público disposto num círculo ao redor do espaço e os corais dependurados no teto:

Figura 1 - Santa Cruz do Não Sei, 2011

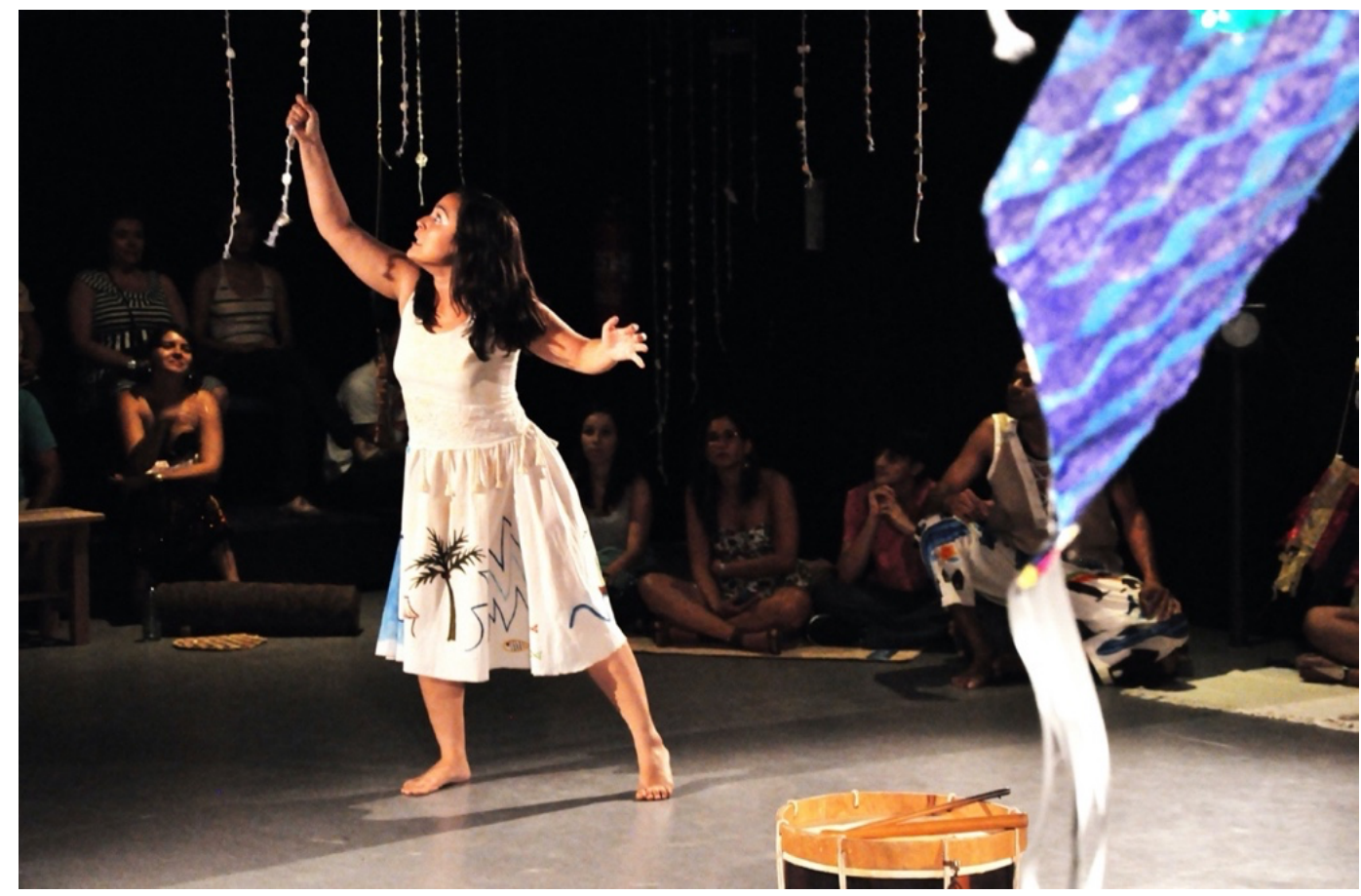

Foto: Marcela Rosseline

Na imagem anterior nós vemos a atriz Paula Medeiros atuando no centro da roda, vemos também o público ao redor, sentado do lado dos atores, a alfaia ao centro e os corais de conchas dependurados. Esta atmosfera gerada pela reconfiguração do espaço e pelos elementos cenográficos possibilitava que o público se transportasse para um outro espaço-tempo, para uma outra dimensão, como sugere Rollemberg (2012). Convém destacar, no entanto, que a criação desta relação espaço-temporal dependia também da utilização do espaço pelos atores, 
que estavam imersos dentro do Jogo Ritual, relação esta que exemplificaremos mais adiante.

O Jogo Ritual ativa a lógica ancestral e esotérica na instauração de um campo mítico, criando uma vivência espacial que se instaura no encontro do espaço concreto, do sagrado e do ficcional, podendo os atores ou as testemunhas ali habitar de forma híbrida no campo borrado resultante do encontro de mais de uma dessas dimensões, ou permanecer em apenas uma dessas, limitando assim a sua experiência. O campo mítico é uma ordem espaço-temporal que extrapola a quinta dimensão do espaço cênico proposto por Rollember, pois, na realidade do mito em ação, e para além do resultado da interação entre os presentes, tornase possível experienciar a própria substância dessa dimensão axis mundi.

Esse campo mítico acionado pelo Grupo Arkhétypos possui características em comum com aquele descrito por Renato Cohen (1996) como resultante de suas pesquisas em Work in progress em que se materializava o que ele compreendeu como duplo, como uma presença fria em uma cena quente, que possibilita a experiência estranha das polaridades, presença/vacuidade, fugacidade/eternidade em um estado de silêncio profundo do ser. Obviamente, tais características se fazem presentes em função da utilização de uma ética budista na essência do processo de criação e da instauração da realidade mítica, diferente do Grupo Arkhétypos que partindo da pesquisa de culturas latino-americanas não entende o corpo como um elemento a ser silenciado para se experienciar o sagrado, mas estabelece a experiência do sagrado a partir da própria potência corporal. O que se apresenta enquanto característica em comum é o percurso do mito pessoal ${ }^{4}$ e da corporificação de figuras arquetípicas como chave para instauração dessa qualidade de experiência espaço-temporal:

Dentro de um processo de criação de natureza ritualística o ator tornase um canal de manifestação das paixões, criando fissuras no tempo e no espaço e permitindo que o inconsciente coletivo (Jung, 2012) se revele

\footnotetext{
O mito pessoal é proveniente dos estudos junguianos que compreendem que o inconsciente possui estrutura mitológica e que cada sujeito possui uma espécie de mito que funciona como tema central, organizando e significando as suas experiências. "Sua mitologia pessoal origina-se dos fundamentos do seu ser, sendo também o reflexo da mitologia produzida pela cultura na qual você vive. Todos criamos baseados em fontes que se encontram dentro e fora de nós e nós vivemos segundo esses mitos." (Feinstein; Krippner, 1992, p. 16).
} 
através das figuras arquetípicas/personagens que se materializam no "jogo ritual". (Haderchpek, 2018, p. 58).

Os atores são agentes que a partir da manipulação de técnicas corpóreas e espirituais consagram o espaço da cena. Contudo, tal qualidade ou categoria espaço-temporal se faz passível de experiência para o público que se relaciona com o acontecimento enquanto um insider, visto que, como apontado por Eliade (1970), o sagrado possui a condição de ser apreendido em sua própria modalidade, exigindo assim que aquele que deseja se relacionar com a sua realidade, esteja integrado ao acontecimento ou realize um deslocamento da realidade imanente para a dimensão da hierofania.

Novamente, deparamo-nos com o conceito base de teatro que formula a maneira com a qual nos relacionamos com o fenômeno e com a experiência de espacialidade que o mesmo possibilita. Ecoando as palavras de Miguel Rubio Zapata (2014, p. 265), membro do grupo peruano Yuyachkani:

O teatro é uma construção cultural que nasce de valores determinados de acordo com a comunidade onde surge, respondendo a relações sociais específicas, como foram as que operaram em diferentes momentos da história. O teatro que chega da Espanha é o teatro do pai, que veio e se impôs ao teatro da mãe, da América pré-hispânica, gerado em contextos ritualísticos, celebrações, jogo, dança, mascaramento. Essas formas seguem vivas e cruzaram o tempo com uma mitologia que as sustenta e desde onde se constroem acontecimentos únicos, que evocam formas ancestrais da representação. As novas gerações não têm modelos e nossas fronteiras cênicas estão saudavelmente movidas. Há zonas cada vez mais indefinidas e nelas novos espectadores. Tudo isso situado em um marco cultural expandido e transuniversal.

Deparamo-nos nas construções do Grupo Arkhétypos com a busca dessa experiência matriarcal do nosso teatro e que nos coloca defronte a questões de um universo e de uma coerência que não são os da ciência positiva, mas o da própria religiosidade. Precisamos de parâmetros de análise que consigam dar conta das zonas indefinidas em que surgem o teatro latino-americano que se relaciona com as práticas rituais, repensando as perspectivas que estão para além daquelas que entendem o acontecimento religioso como simples resultado da interação ideológica social, compreendendo-o como um elemento autônomo que 
compõe o social. E neste sentido, a concepção de mundo interfere diretamente na construção simbólica da cena e dos elementos cênicos que a constituem. Assim, podemos utilizar a reflexão que Sylvio Fausto Gil Filho realiza sobre a religião e o sagrado para analisar a relação existente entre Jogo Ritual e o sagrado: "Reduzir a religião totalmente como reflexo das relações contraditórias da sociedade não explica o mais fundamental, ou seja, seu caráter sagrado. A permanência do sagrado impõe uma renovada abordagem do fenômeno religioso." (Gil Filho, 1999, p. 97).

O espaço cênico do Jogo Ritual ocorre na descontinuidade imprimida ao mundo sensível em um adensamento da experiência em seu caráter numinoso (Jung, 2008). Quando adentra-se o espaço do Jogo Ritual a sala de ensaio deixa de ser uma simples sala de ensaio com paredes e janelas sendo ressignificada a partir do envolvimento do ator com o universo mágico-ficcional trabalhado no jogo. Na realidade, o espaço da sala de ensaio é subvertido através da imaginação do ator tornando-se um espaço mágico-simbólico.

No Jogo Ritual, tanto o ator como o público operam a partir de estados alterados de consciência, e tal preceito atua como um facilitador no processo de ressignificação do espaço. Operando a partir desta relação com o inconsciente e com o imaginário, o espaço da sala de ensaio ou da apresentação ganham um novo sentido. No Jogo Ritual o espaço-tempo não é linear e as espacialidades se sobrepõem. Neste sentido, o ator pode estar em dois lugares ao mesmo tempo e ainda assim convencer o público dessa possibilidade. Ao se deslocar da realidade imanente o ator leva o público consigo e o projeta no espaço-tempo da hierofania 5 .

Enquanto, podemos compreender o espaço ficcional como um duplo da materialidade, o espaço sagrado se manifesta em um rasgo em meio às duas lógicas operantes, material e ficcional, tornando aquele "solo" um espaço sagrado e criando uma experiência oposta à toda aquela possibilitada no âmbito do profano, incluindo imediatamente o público no ato cênico, e transformando-o em

Na página do Grupo Arkhétypos nós disponibilizamos os teasers dos espetáculos e informações adicionais sobre os processos, caso haja interesse: https://arkhetyposgrupodet.wixsite.com/arkhetypos/santa-cruzdo-nao-sei e https://arkhetyposgrupodet.wixsite.com/arkhetypos/revoada. Acesso em: 01 de jul. 2020. 
agente ativo no jogo: "Dentro do "jogo ritual” nós convidamos o público para observar as ações mágicas do ator e entrar na história com ele" (Haderchpek, 2018, p.58). O ritual, seja ele qual for, exige dos que o integram uma profunda adesão ${ }^{6}$ psicofísica aos símbolos que ele opera. Tal adesão gera uma espécie de porosidade que permite que o sagrado se manifeste, seja na coagulação de conteúdos do inconsciente, seja na percepção psicofísica de uma espécie de duplo da materialidade. A seguir descreveremos como se dá esse fenômeno nos espetáculos Santa Cruz do Não Sei e Revoada.

Essa diferença qualitativa do espaço sacralizado pode ser observada, como aponta Gil Filho, em "um templo religioso [pois] notamos que o espaço por ele circunscrito é qualitativamente diferenciado pela sacralização, sendo essa separação interna um constrangimento de uma oposição ao vazio da natureza externa, ao mesmo tempo que separa, também restabelece a natureza noutra ordem" (Gil Filho, 1999, p. 111-112). Mas, note que tal sacralização não existe por si enquanto dado material, mas é possibilidade enquanto uma experiência que surge a partir de condições pré-existentes no espaço e no sujeito que se relaciona com o mesmo.

Os trabalhos do Grupo Arkhétypos sempre carregam em si uma forte relação com o sagrado, um sagrado que se manifesta no corpo dos atores e que se estende para o espaço cênico, tornando esse espaço um lugar sacro. A maneira como os atores usam o espaço e atribuem significado ao espaço tornam esse espaço sagrado. Quando iniciamos o Jogo Ritual, por exemplo, nós preparamos o espaço para que o jogo aconteça, dispomos os elementos cênicos que serão utilizados e deixamos que o corpo dos atores ressignifique os objetos. Tanto no espetáculo Santa Cruz do Não Sei, relatado anteriormente, como no Revoada, que relataremos a seguir, nós trabalhamos com objetos, imagens e sonoridades que aludem a universos religiosos e oníricos. No espetáculo São Cruz do Não Sei, por exemplo, uma das atrizes acendia uma vela e levava um copo com água para um

6 O Jogo Ritual é um procedimento de criação do Grupo Arkhétypos, havendo interesse outros artigos sobre o assunto podem sem consultados: a) Robson Carlos Haderchpek. 2018. b) Karyne Dias. Coutinho e Robson Carlos Haderchpek, 2019. 
determinado lugar do espaço cênico, um lugar demarcado ao redor de um círculo. A partir desta ação, este lugar passava a ser lido pelos demais atores e pelo público como o altar de Yemanjá, e assim, a ação simbólica da atriz ressignificava o espaço. A ação cerimonial e a alteração das dinâmicas corporais que a mesma exige em conjunto com os símbolos que emergem dela evocam o conjunto de crenças do público. Para além disso, quando o ator consegue a partir do trabalho psicofísico tornar-se um veículo para os conteúdos arquetípicos, acessando o universal que existe na profundeza do individual, ele coopta o outro para dentro de si. E então, aquele silêncio pleno, denso e a sensação, que por vezes acontece na experiência teatral, de que o espaço vazio está preenchido por algo surge.

Quando essa ação de desvelamento do ator, de transformação do corpo em medium é bem sucedida, o corpo do público responde modificando também a sua qualidade de presença e dessa forma a sua relação com o tempo-espaço. A crença de que aquele espaço era um lugar sagrado, fazia com que todos tivessem um cuidado com ele, e mesmo quando terminava o espetáculo, as pessoas ainda o tratavam com zelo.

Através da atmosfera mágico-simbólica construída no Jogo Ritual, o espaço cênico é ressignificado e passa interagir com o imaginário dos atores e do público, construindo pontes de conexão com o numinoso, sem que haja necessidade de uma separação entre o material e o ficcional. O espetáculo Revoada, por exemplo, fez várias apresentações num espaço alternativo onde funcionava uma escola primária. Sem mexer na estrutura física do espaço, o Grupo Arkhétypos tinha a missão de transformar ${ }^{7}$ aquela escola num lugar onde tanto os atores como o público pudessem cruzar sete espaços sagrados e viver uma jornada mítica.

Segundo a professora e pesquisadora Laura Maria de Figueiredo, iluminadora e cenógrafa do espetáculo Revoada, terceiro trabalho cênico do Grupo Arkhétypos:

Na última década do século XIX e na primeira metade do século XX, antes da segunda guerra mundial, diversos artistas e pensadores do Teatro se voltaram contra as convenções do Palco Italiano, seus truques e suas

Para mais informações sobre a transformação do uso do espaço consultar: Laura Figueiredo Maria. Um voo para o reencontro com o sagrado na prática teatral. In: Robson Carlos Haderchpek (Org.). Arkhétypos Grupo de Teatro: Encontros e Atravessamentos. Natal: Fortunella Casa Editrice, 2017. 
tecnologias cênicas voltadas para a ilusão e para movimentos miméticos que enchiam os olhos de suas plateias, mas atrofiavam sua imaginação e capacidade de vidências além das aparências dos fenômenos da realidade. (Figueiredo, 2017, p. 103).

Ao longo de sua trajetória artística Laura Figueiredo atuou com iluminadora profissional em São Paulo e desenvolveu trabalhos sob diversas perspectivas e linguagens, mas quando chegou no Grupo Arkhétypos, afirma ter reencontrado as raízes de um teatro sagrado. De acordo com a pesquisadora:

O trabalho no processo de elaboração do espetáculo Revoada em 2014 me trouxe de volta ao núcleo pulsante desta perspectiva sobre a intervenção num espaço repleto de frescor e vitalidade, onde se busca criar uma zona de comunicação e de integração de energias entre a cena e a plateia de cada apresentação, através do invisível tornado visível, onde as grandes questões humanas de vida, morte, amor, transcendência, corpo e espirito foram evidenciados em formas materiais artesanais, isto é, feitas por corpos e mentes, mãos e corações integrados por um objetivo estético, mas ao mesmo tempo prático e necessário, a partir dos recursos que se dispõe nas trocas inter-humanas e nos materiais que se apresentavam como soluções técnicas para a construção poética. (Figueiredo, 2017, p. 104).

O espetáculo Revoada foi criado a partir do Jogo Ritual e inspirado no conto persa A Conferência dos Pássaros, escrito por Farid Ud-Din Attar no século XII. O espetáculo foi pensado a partir de uma relação íntima dos atores com o espaço, visto que no conto original, os pássaros precisavam cruzar sete vales para encontrar o seu rei, chamado Simorg. Tal como os demais trabalhos do grupo, o Revoada também rompe com a proposta de um palco convencional e propõe um percurso itinerante. Ao longo do espetáculo trinta espectadores/participantes deveriam cruzar sete vales: 1) Busca; 2) Amor; 3) Desapego; 4) Compreensão; 5) Morte; 6) Unidade; 7) Deslumbramento. Em cada espaço o corpo dos atores se portava de uma determinada maneira ajudando a instaurar uma relação ritualística com a cena e conectando o público a um imaginário mítico, nos permitindo repensar a nossa relação com o sagrado.

\footnotetext{
${ }^{8}$ A palavra Simorg em persa significa "trinta pássaros", e este é o número de pássaros que chega ao final da jornada, segundo o conto original. Com base nesta informação o Grupo Arkhétypos definiu que o número de espectadores que participaria do espetáculo Revoada também seria trinta.
} 
Para exemplificar, voltemos ao exemplo do uso da água e das velas. No espetáculo Revoada a água era colocada em bacias e cumbucas, e elas serviam para lavar as mãos do público na entrada do vale do amor. Na entrada do vale, dois pássaros lavavam as mãos do público, esta ação simbólica de lavar as mãos do público ressignificava o espaço, evocando a memória do ato de se benzer ou se purificar típico dos espaços sagrados. Em seguida, dentro do vale, os pássaros se banhavam em bacias cheias de água (Figura 4) e contemplavam as velas acesas, que projetavam sombras na parede e faziam o espaço ganhar uma atmosfera onírica. As sombras pairando no espaço junto às luzes que criavam um ambiente imaginal remetiam a seres míticos, que se multiplicavam pelo espaço como uma revoada que trazia à tona entidades mágicas. É da natureza deste tipo de processo, suscitar imagens arquetípicas e estas por sua vez, ao se manifestarem, tornam o espaço sagrado.

Laura Figueiredo, traçando paralelos entre o trabalho do Grupo Arkhétypos e a proposta de Peter Brook lançada em 1968 no livro O teatro e seu espaço (2015), afirma:

Neste sentido posso caracterizar o processo vivido na construção do Revoada como esse ponto de cruzamento de várias referências poéticas e várias energias criativas para buscar um momento de comunhão ritual com a plateia da vez, em espaços alternativos que seriam sempre transformados pela ativação de um imaginário mítico e metafisico em sua essência, e dessa forma muito ligada ao Teatro Sagrado [...] (Figueiredo, 2017, p. 104).

Tal como o espetáculo Santa Cruz do Não Sei citado no início deste artigo, o espetáculo Revoada também propõe ao espectador que ele rompa com o espaçotempo convencional e seja transportado para uma outra dimensão, porém, diferente da primeira proposta que era circular, nesta última, o público deveria migrar entre os sete vales, tornando-se nômade.

Sem conhecer a mitologia do povo Achilpas, o Grupo Arkhétypos recriou as bases cosmológicas da mitologia de Numbakula, narrada por Mircea Eliade (1979). Contudo, em vez de carregarem consigo um tronco de eucalipto, os trinta espectadores carregavam uma pequena almofada que thes servia de acento, e que 
também lhes permitia adentrar ao universo mágico-simbólico de cada vale, possibilitando uma experiência numinosa (Jung, 2012). Vejamos a seguir algumas fotos do espetáculo que apresentam de forma visual o que vimos relatando até o presente momento.

Figura 2 - Revoada, 2015. Instante em que os atores se preparam para encontrar o público. Local: Pinacoteca Potiguar, Natal (RN)

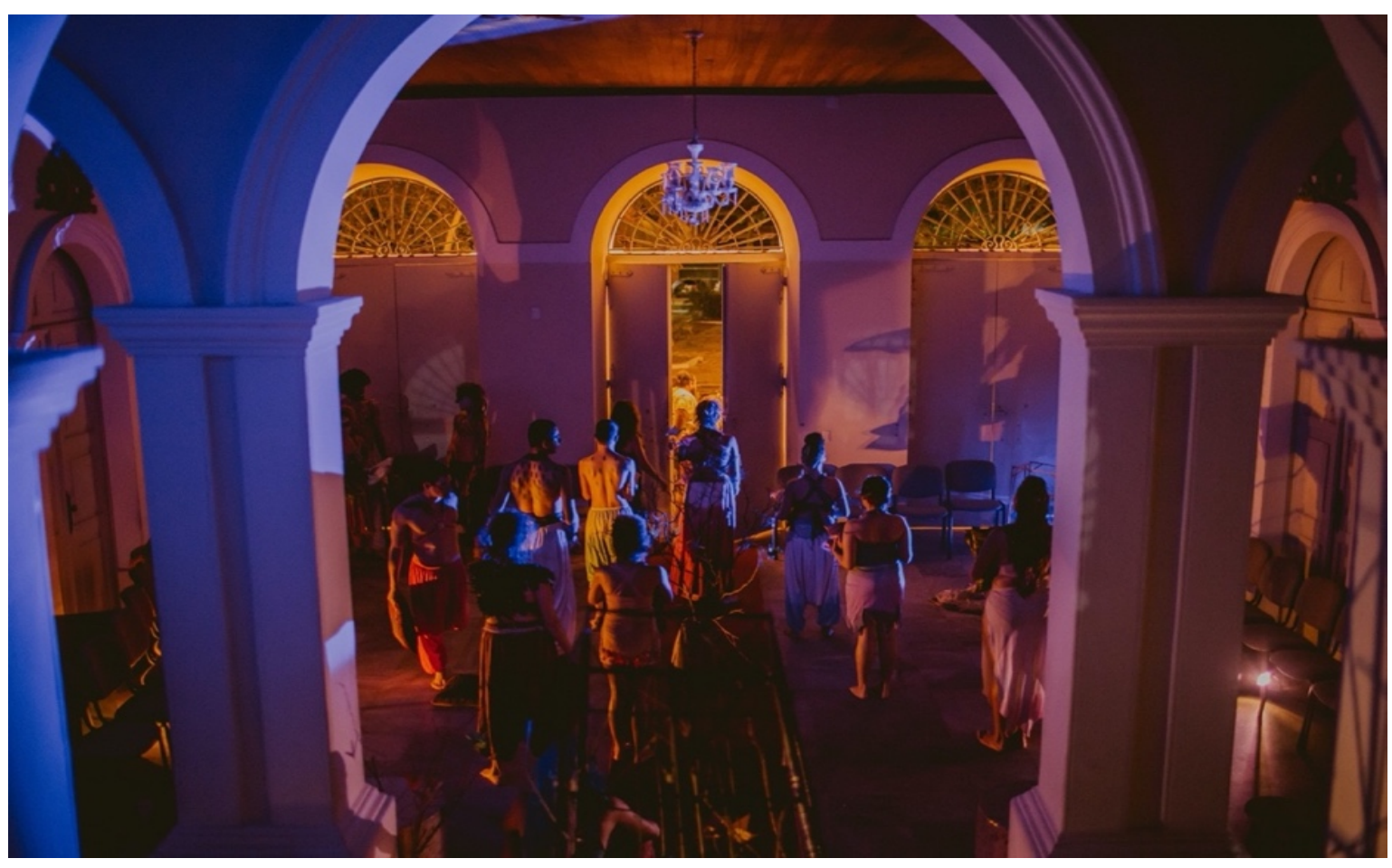

Foto: Diego Marcel 
Figura 3 - Revoada, 2015. Momento em que o público recebe as almofadas. Local: Pinacoteca Potiguar, Natal (RN)

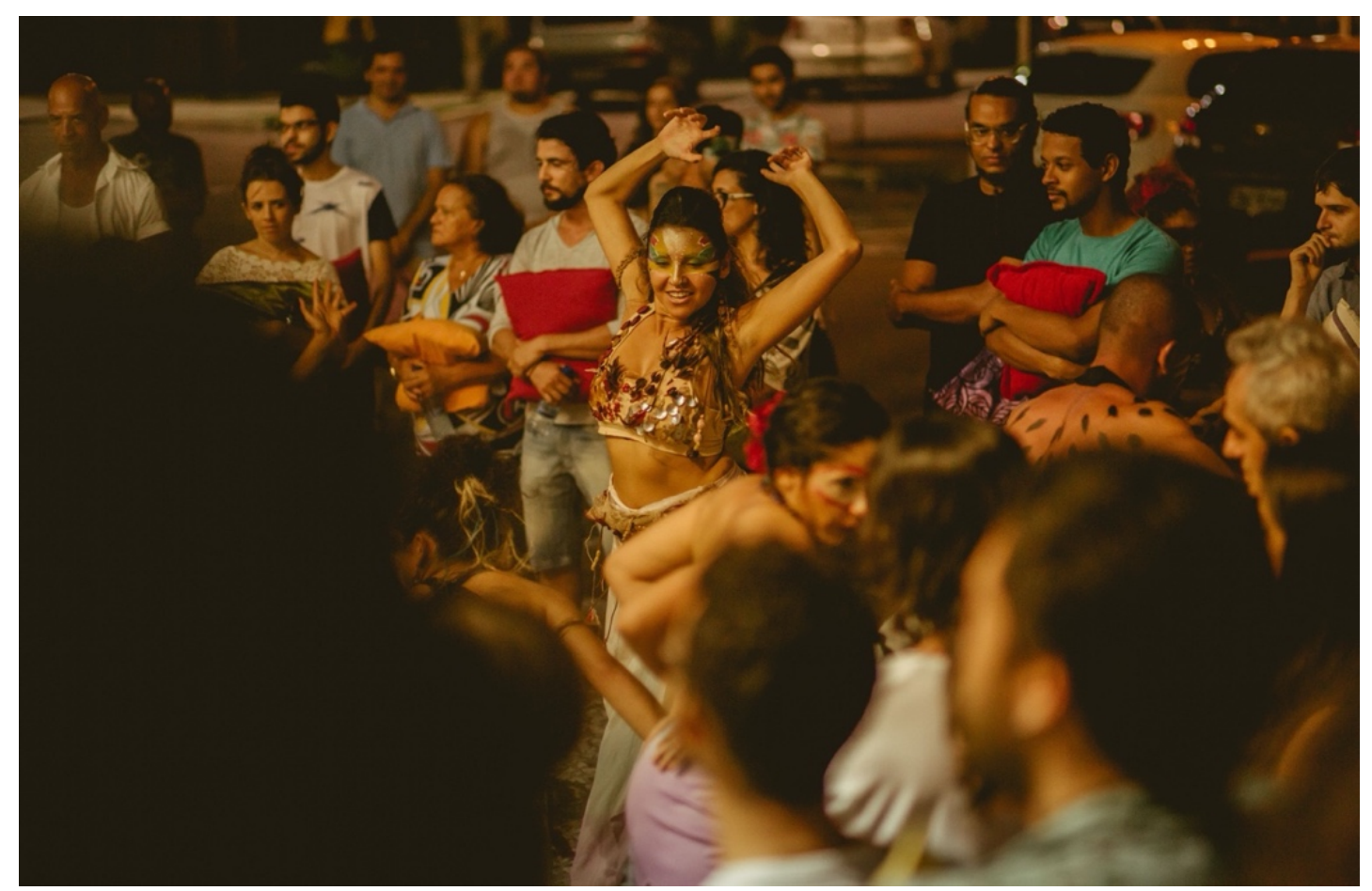

Foto: Diego Marcel

Figura 4 - Revoada, 2015. Público sendo recebido no Vale do Amor

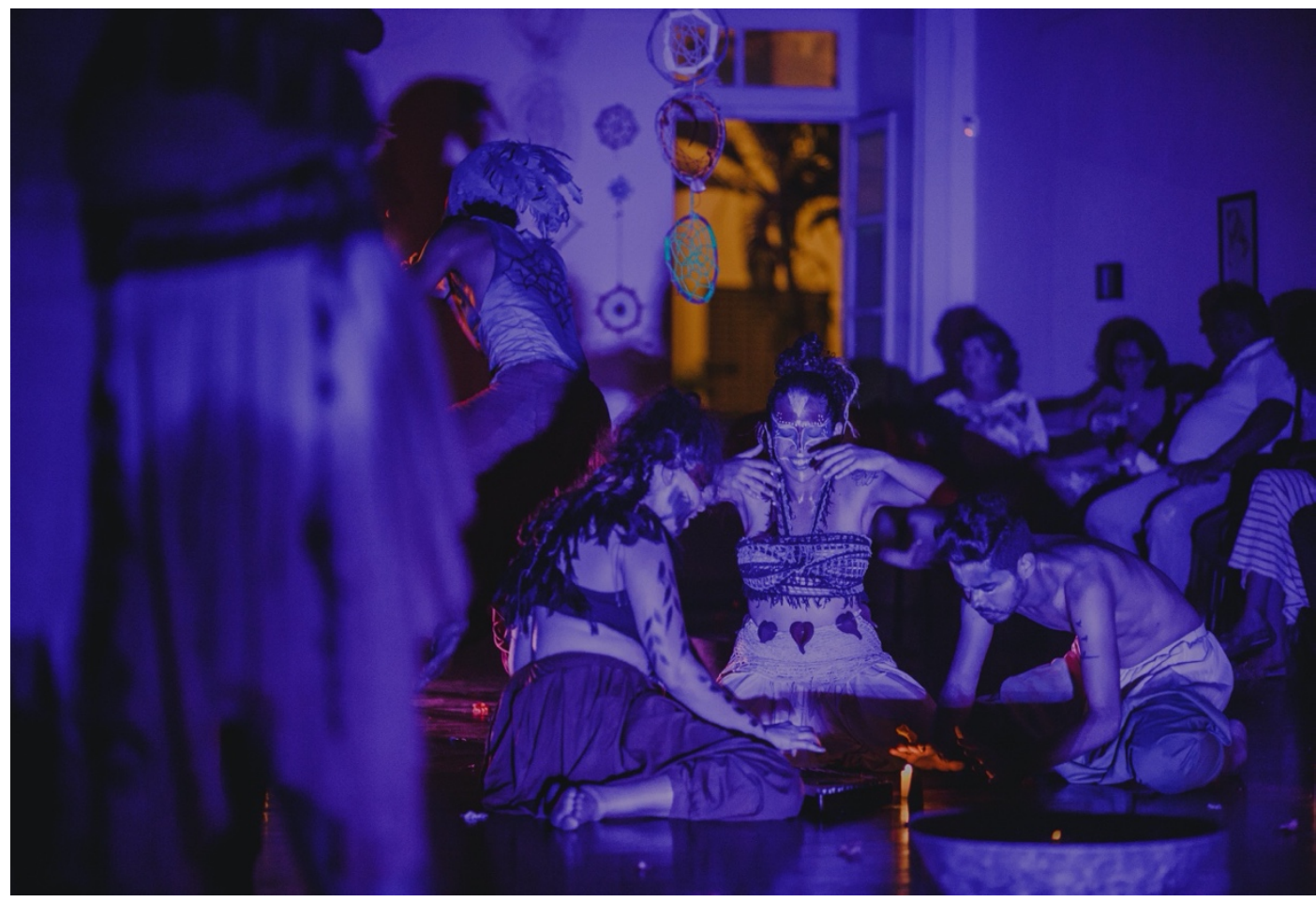

Foto: Diego Marcel 


\section{Urdimento}

O Axis Mundi e o Jogo Ritual:

Deslocamento da realidade imanente para se alcançar a Hierofania

Figura 5 - Revoada, 2015. Público participando do Vale da Compreensão

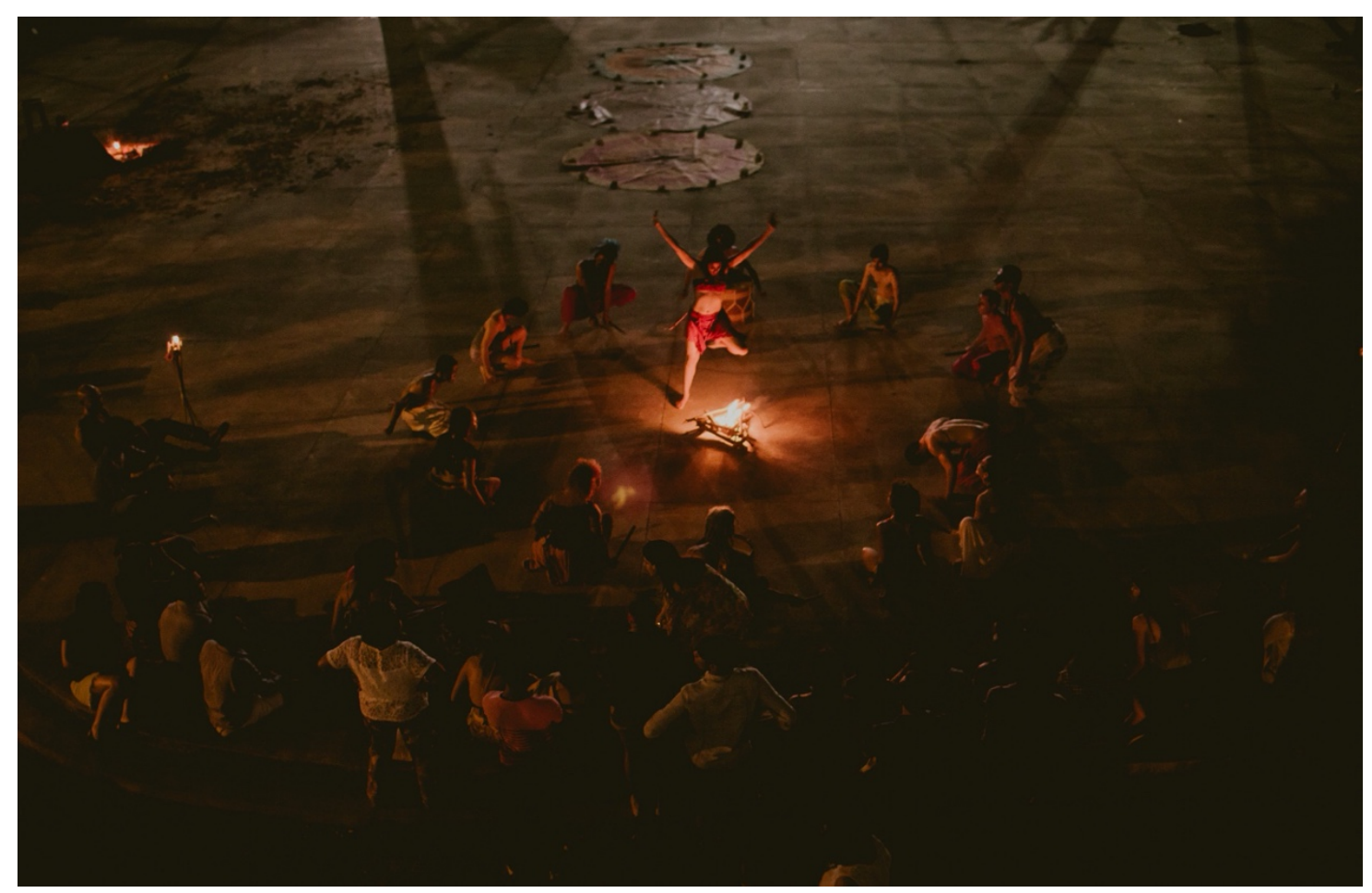

Foto: Diego Marcel

Figura 6 - Revoada, 2014. Vale da Unidade. Local: TECESOL, Natal (RN)

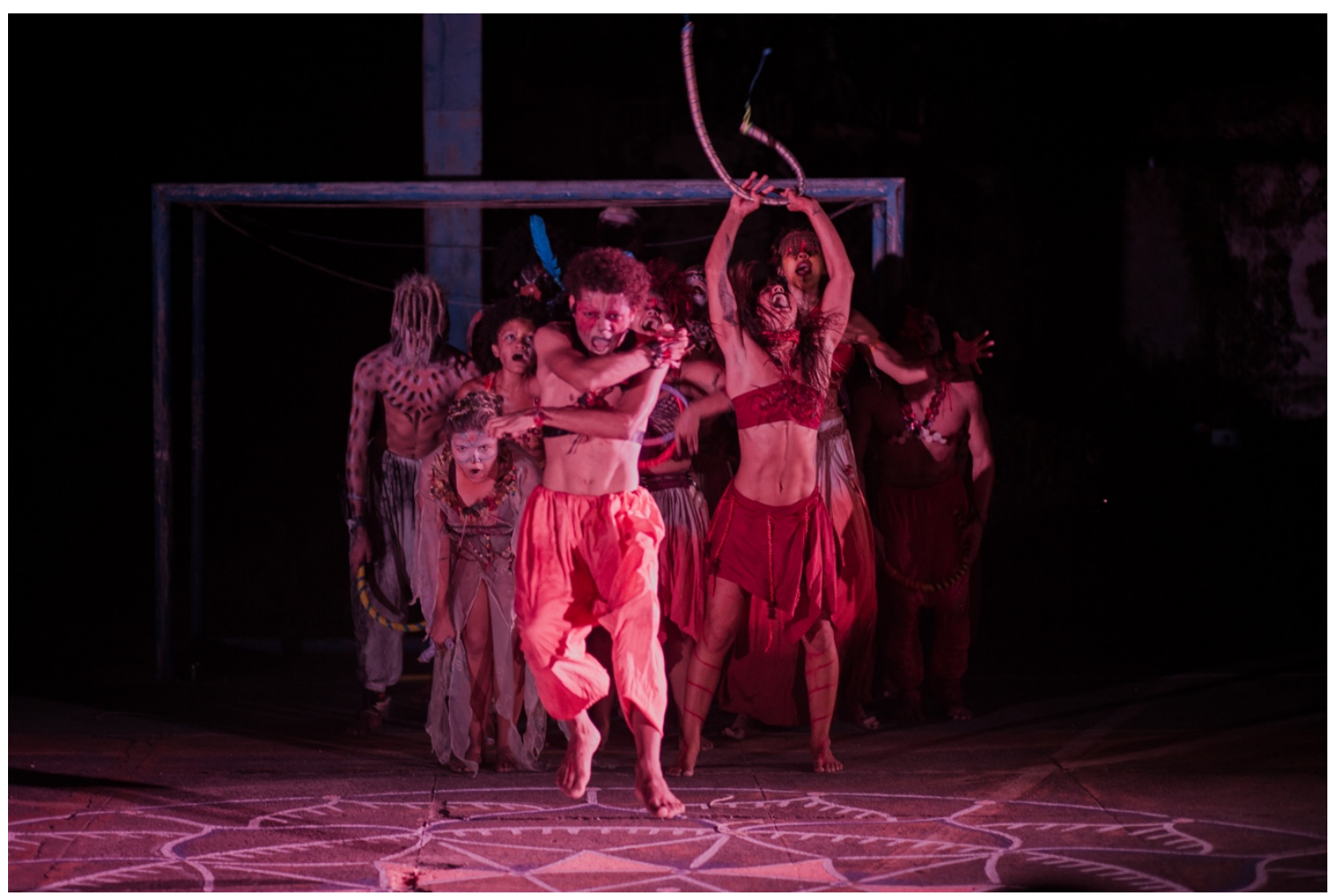

Foto: Diego Marcel 
Figura 7 - Revoada, 2014. O público voa junto com os atores no Vale da Deslumbramento. Local: TECESOL, Natal (RN)

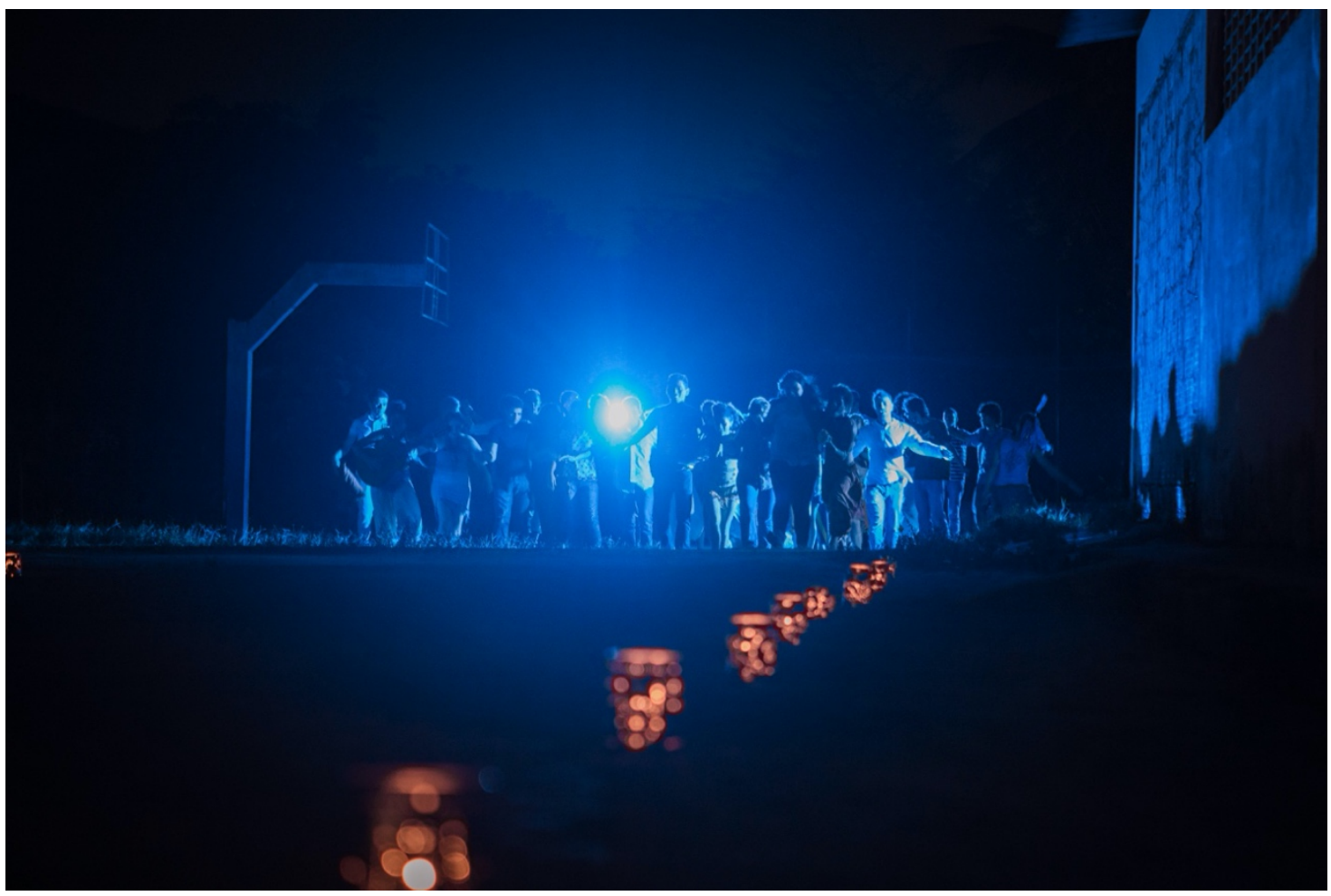

Foto: Diego Marcel

Em cada vale o espectador era conduzido de uma maneira, e em cada espaço ele construía um tipo de relação com o universo mágico-simbólico que se apresentava diante dele. Por exemplo, no vale da compreensão (Figura 5) o público se colocava ao redor de uma fogueira e ao som das alfaias participava de uma cerimônia de renascimento. Se observarmos a última imagem (Figura 7), por exemplo, veremos o público com os braços abertos voando junto com os atores para cruzar o último portal. É assim que o Grupo Arkhétypos cria espaços que carregam em si a condição de axis mundi e transporta o público para um tempoespaço mítico que propicia a atores e espectadores uma reconexão com o sagrado que habita em si.

Quando o público está imerso no Jogo Ritual, ele ajuda o ator a construir cenicamente o espaço do rito, subvertendo o espaço do real e adentrando o tempo-espaço mítico. No vale da compreensão (Figura 5), citado anteriormente, a disposição circular ajuda a criar o espaço do rito, e remete à circularidade que 
mencionamos no início deste texto. Já no vale do deslumbramento (Figura 7), a ação de cruzar o último portal se dá numa linha reta deslocando o público para o mesmo espaço-tempo simbólico em que estão os atores. Deste modo, o público toma parte na ação que está sendo realizada e vive a experiência numinosa9 (Jung, 2008) junto com os atores, reconectando-se com as suas origens míticas.

\section{As Origens Míticas do Imaginário e a Hierofania}

O mito encarnado no espaço-temporal do rito é capaz de nos alçar a outro patamar de percepção sobre nós e sobre a realidade em que estamos inseridos, e esta é uma característica do Jogo Ritual, proposto com o intuito de incorporar em seu modus operandi os saberes que nos foram relegados e/ou desconsiderados no processo de colonização da América pré-colombiana.

Uma das formas de se dominar um povo é dominando o seu imaginário e foi por isso que quando os europeus chegaram às Américas eles trouxeram consigo os padres jesuítas. Os padres, representantes da igreja católica, tinham a missão de introjetar nas vidas e nos costumes dos povos originários, uma cultura e um deus que não eram deles. O primeiro passo para isso foi exterminar a cultura local, os ritos, as crenças e a formas de ser da população que habitava essas terras. Destruíram a concepção de sagrado que habitava o imaginário local e impuseram uma forma de sagrado que passaria por um intercessor maior, a igreja. Para tanto, demonizaram seus corpos, sua relação com a natureza, incutiram em suas mentes a ideia de pecado, menosprezaram suas histórias e deturparam a sua maneira de pensar:

As culturas antigas da Abya Yala passavam dias inteiros dançando, recriando as energias do universo junto a seus mitos e Deuses. $\mathrm{Na}$ episteme Amerindia nós teríamos a máxima: "Eu danço e logo existo", não como em Descartes, pai da racionalidade: "Eu penso, logo existo." (Vargas e Haderchpek, 2017, p. 79).

9 Para Jung os arquétipos (2008, p. 122): "são ao mesmo tempo imagem e emoção; e só podemos nos aferir a arquétipos quando esses dois aspectos se apresentam simultaneamente. Quando existe apenas a imagem, ela equivale a uma descrição de pouca importância. Mas quando carregada de emoção, a imagem ganha numinosidade (ou energia psíquica) e torna-se dinâmica, acarretando várias consequências." 
Antes dos colonizadores chegarem às Américas os povos originários tinham outra forma de se relacionar com o tempo e com o espaço, eles tinham também outra maneira de pensar e de se conectar com o sagrado, mas o ocidente não respeitou isso. Quando os colonizadores chegaram nas Américas eles trouxeram consigo um padrão de pensamento que priorizava o conhecimento lógico-racional, desprezando os fenômenos cósmicos e a temporalidade mítica. Historicamente, o ocidente sempre teve uma dificuldade de reconhecer a importância de um conhecimento intuitivo, não-lógico e tido como "primitivo". Segundo Gilbert Durand, estudioso das teorias do imaginário:

Embora, por um lado, tenha sido a lenta erosão do papel do imaginário na filosofia e epistemologia do ocidente que possibilitou o impulso enorme do progresso técnico, por outro, o domínio deste poder material sobre as outras civilizações atribuiu uma característica marcante ao "adulto branco e civilizado", separando-o assim como sua "mentalidade lógica", do resto das culturas do mundo tachadas de "pré-lógicas", "primitivas" ou "arcaicas". (Durand, 1998, p.15).

O adulto branco civilizado que chegou às Américas matando, estuprando e escravizando para favorecer um sistema econômico e impulsionar o progresso, precisava criar uma cisão no imaginário local a fim de implantar um novo projeto de vida e de organização social. As pessoas não poderiam passar dias dançando, expondo seus corpos nus e adorando os seus deuses, pois isso tiraria o foco da produção e consequentemente inviabilizaria o processo de dominação. Então, criaram uma estratégia para aniquilar todo e qualquer resquício dos mitos locais, impondo a sua cultura e a sua forma de sagrado aos povos originários. Mataram o tempo mítico, retiraram das pessoas o direito de imaginar, de dançar, e de se conectar com o não-lógico, ou melhor, com o alógico:

[...] o imaginário, nas suas manifestações mais típicas (o sonho, o onírico, o rito, o mito a narrativa da imaginação etc.) e em relação à lógica ocidental desde Aristóteles, quando não a partir de Sócrates, é alógico. A identidade não-localizável, o tempo não assimétrico e a redundância e metonímia "halográfica" definem uma lógica "inteiramente outra." (Durand, 1998, p.87). 
Para Durand o rito e o mito são manifestações do nosso imaginário que obedecem a uma outra lógica e, portanto, valorizam um campo do saber que é não-racional:

O mito não raciocina nem descreve: ele tenta convencer por repetição de uma relação ao longo de todas as nuanças (as "derivações", como diria um sociólogo) possíveis. A contrapartida dessa particularidade é que cada mitema - ou cada ato ritual - é o portador de uma mesma verdade relativa à totalidade do mito ou do rito. (Durand, 1998, p.86).

Daí a importância de se propor um resgate desses saberes, e o Jogo Ritual atua exatamente nessa dimensão da repetição e da ativação dos mitemas ${ }^{10}$ que habitam o nosso inconsciente, e Durand (1998, p. 35-36) completa:

[...] o psiquismo humano não funciona apenas à luz da percepção imediata e de um encadeamento racional de ideias, mas também, na penumbra, ou na noite de um inconsciente, revelando aqui e ali, as imagens irracionais do sonho, da neurose ou da criação poética.

As poéticas do inconsciente perderam espaço na sociedade produtivista e herdeira de um processo de colonização devastador. As pessoas não se permitem sonhar, não tem tempo para isso, pois o tempo que elas obedecem é o tempo do capital, o tempo do progresso e o mito, não tem apenas uma "outra lógica" como também obedece a um outro tempo. Por isso, quando conseguimos transportar o público para um universo paralelo, para um outro espaço-temporal, estamos de algum modo nos conectando com um outro tipo de saber, e uma outra concepção de sagrado, que não aquela imposta no processo de colonização.

Durand nos fala também do ilud tempus do mito (1998, p.80), baseado em Eliade, afirmando que os fenômenos míticos se situam num espaço e num tempo completamente diversos:

Aqui, trata-se do ilud tempus do mito, que - segundo Eliade, o qual também é um romancista e escreveu narrativas profanas como o conto, a legenda, o romance... - contém seu próprio tempo numa espécie de relatividade (generalizada!) bem específica e "não-assimétrica" (Oliver Costa de Beauregard), onde o passado e o futuro independem entre si e

10 Segundo Durand: "Mitema - Uma narrativa puramente ficcional. Geralmente envolve pessoas, ações ou eventos supernaturais e incorpora alguma ideia popular referente a um fenômeno natural ou histórico, in EOD (English Oxford Dictionary). (NT)." (1998, p. 86). 
os eventos são passíveis de reversão, de uma releitura, de litanias e rituais repetitivos... (Durand, 1998, p.80).

Quando se trata do mito, o tempo e o espaço se manifestam de maneira imbricada. E pensando na citação de Durand, podemos dizer que ilud tempus do mito contém em si o ilud locus do mito também, pois sob a perspectiva mítica o tempo e o espaço extrapolam os limites convencionais da realidade imanente e se configuram a partir de dimensão simbólica. É isso o que fazemos quando acionamos o Jogo Ritual, propomos aos atores e ao público uma suspensão temporária do espaço-tempo convencional e adentramos ao espaço-tempo da hierofania, da manifestação do sagrado, onde passado e futuro independem entre si e onde os eventos são passíveis de reversão, daí a importância da repetição, pois os ritos se refazem e as histórias mudam tal como o nosso imaginário.

Quando voltamos às nossas origens míticas, quando voltamos ao tempo mítico, e nos conectamos com o axis mundi (Eliade, 1979a) nós temos a oportunidade de recriar a nossa história, recriar a nossa conexão com o sagrado e nos empoderamos enquanto sujeitos, livres e autônomos, donos de um saber “alógico" (Durand, 1998) e não-racional.

E assim, quando referenciamos os espetáculos "Santa Cruz do Não Sei" e "Revoada", estamos citando exemplos de reorganização do espaço-tempo, estamos recriando o tempo da hierofania e estamos operando a partir de uma "outra lógica”, a lógica do imaginário.

\section{Considerações Finais}

Após esta breve reflexão sobre os processos de criação do Grupo Arkhétypos, e após a análise dos espetáculos supracitados à luz do Jogo Ritual, reiteramos a importância relacional do uso do espaço cênico (Rollemberg, 2012) tomando como referência as teorias do imaginário (Durand, 1988) e a necessidade de reorganização do espaço-tempo simbólico a partir de uma "outra lógica”, não racional. 
Entendemos como fundamental neste tipo de processo, a reinvenção do uso do espaço cênico pelos atores e pelo público, não penas na perspectiva do espaço físico, material, como também do espaço metafísico, o espaço do axis mundi (Eliade, 1979a), o eixo cósmico que liga o céu, a terra e o subterrâneo na dimensão metafórica. Para tanto, nos apoiamos no estudo dos mitos, dos ritos e das imagens que brotam do nosso inconsciente.

Lembramos ainda que o processo de colonização das Américas, realizado pelo homem branco e civilizado, buscou aniquilar as crenças e os costumes dos povos originários, impondo-lhes outro modelo de sagrado e outro padrão de pensamento que obedece a lógica racional e produtivista, pautada nos ideais de progresso.

Analisando as teorias do imaginário sob uma perspectiva histórica, compreendemos a importância ilud tempus do mito (Durand, 1998) e entendemos que uma das formas de se descolonizar um povo é descolonizando o seu imaginário. Entendemos também que as imagens são portais de reconexão com o sagrado, não o sagrado no sentido das instituições religiosas, mas o sagrado no sentido da experiência numinosa (Jung, 2008), da reconexão do sujeito consigo mesmo e com as suas origens míticas: "Para Jung, a imagem, por sua própria construção, é um modelo de autoconstrução (ou individuação) da psique." (Durand, 1998, p.37).

Durand (1998) dialoga com Jung (2008) e dialoga também com Eliade (1979a), e todos eles nos ajudam a refletir sobre os processos de reinvenção e reinterpretação do espaço-tempo na dimensão da psique, do simbólico, do imaginário e da cena. E neste sentido, compreendemos que o deslocamento da realidade para se alcançar a hierofania acontece a partir da experiência mítica corporificada nas ações mágico-simbólicas do ator, que são comungadas com o público, reconfigurando a relação espaço-temporal da cena. 


\section{Referências}

BROOK, Peter. O teatro e seu espaço. Rio de Janeiro: Apicuri, 2015.

CHIESA, Gustavo Ruiz. A eficácia múltipla (ou a multiplicidade de um conceito antropológico). Revista Brasileira de Ciências Sociais. São Paulo, v. 29, n. 86, p. 143145, 2014.

COHEN, Renato. Work in Progress na cena Contemporânea. São Paulo, Perspectiva, 1998.

COUTINHO, Karyne Dias; HADERCHPEK, Robson Carlos. Pedagogia de Si: Poética do Aprender no Teatro Ritual. In ART RESEARCH JOURNAL / Revista de Pesquisa em Artes, Natal, v. 6 n. 1, p. 01-21, 2019.

DURAND, Gilbert. O imaginário: ensaio acerca das ciências e da filosofia da imagem. Rio de Janeiro: DIFEL, 1998.

ELIADE, Mircea. Imagens e símbolos. Lisboa, Ed. Arcádia, 1979a.

ELIADE, Mircea. Ocultismo, bruxaria e correntes culturais. Belo Horizonte: Interlivros, 1979b.

FEINSTEIN, David \& KRIPPNER, Stanley. Mitologia pessoal: a psicologia evolutiva do self. São Paulo: Cultrix, 1997.

FIGUEIREDO, Laura Maria. Um voo para o reencontro com o sagrado na prática teatral. In: HADERCHPEK, Robson Carlos (org). Arkhétypos Grupo de Teatro: Encontros e Atravessamentos. Natal: Fortunella Casa Editrice, 2017.

FOUCAULT, Michel. (1926-1984). O corpo utópico, as heterotopias. São Paulo. N-1 Edições, 2013.

GIL FILHO, Sylvio Fausto. Espaço de representação e territorialidade do sagrado: notas para uma teoria do fato religioso. Raega, Curitiba, v. 3, p. 101-120, 1999.

HADERCHPEK, Robson Carlos. O Jogo Ritual e as Pedagogias do Sul: Práticas Pedagógicas para a Descolonização do Ensino do Teatro. Revista Moringa - Artes do Espetáculo, João Pessoa, v. 9, n. 1, p. 55-65, 2018.

JUNG, Carl G. Os Arquétipos e o Inconsciente Coletivo. Petrópolis: Vozes, 2012.

JUNG, Carl G. O Homem e seus Símbolos. Rio de Janeiro: Nova Fronteira, 2008.

LIGIÉRO, Zeca. Teatro das Origens: estudo das performances afro-ameríndias. Rio 
de Janeiro: Garamond, 2019.

ROLLEMBERG, Doris. A cenografia além do espaço e do tempo. O teatro de dimensões adicionais. O Percevejo Online, Rio de Janeiro, v. 4, n. 2, p. 1-22. 2012.

VARGAS, Rocio del Carmen Tisnado. HADERCHPEK, Robson Carlos. O Sul Corpóreo e a Poética dos Elementos: Práticas para a Descolonização do Imaginário. Revista ILINX: Revista do Lume, Campinas, n. 10, p. 77-87, 2017.

ZAPATA, Miguel Rubio. O teatro e nossa América. Urdimento - Revista de Estudos em Artes Cênicas, Florianópolis, v. 1, n. 22, p. 259-266, 2014.

Recebido em: 08/05/20

Aprovado em: 03/07/20 